\title{
Uppsala University honours Sri Lankan scientist- Prof. Tissa Illangasekare
}

Prof. Tissa Illangasekare holds the Amax Distinguished Chair of Environmental Science and Engineering

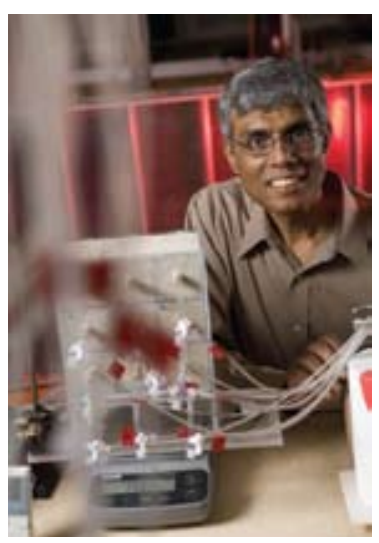
and is a Professor of Civil Engineering and Director, Center for the Experimental Study of Subsurface Environmental Processes (CESEP) at the Colorado School of Mines, USA - the top ranked earth resources engineering school in the world. He is an alumnus of the University of Peradeniya. He has been awarded an honorary doctorate by the Uppsala University in Sweden for his outstanding contribution to the field of contaminant hydrology. He is also the current Editor of the Journal of Water Resources Research.

Uppsala University is one of the oldest universities in Europe that started in 1477 . The honorary doctorate system at Uppsala University was established in 1839. It has a long history of excellence with 15 Noble Laureates. Prof. Tissa Illangasekare has been honoured for his contribution in the general area of Natural Science and Technology. The previous recipients of this honour in 2007/2008 were Sir David Attenborough (zoologist, naturalist and broadcaster), Dame Dr. Jane Goodall (famed primatologist) and Michel Mayor (Swiss astronomer and planetary scientist). He will go to Sweden next year to receive this honour at a very elaborate academic ceremony that includes firing of cannon shot for each honoree (he gets to keep the shell casing!).

The citation for this honour released by Uppsala University is as follows: "The Faculty of Science and Technology at Uppsala University has appointed two new honorary doctors for the year 2009. Evolutionary biologist, Professor Marlene Zuk, who is a leading authority on the role of parasites in sexual selection in birds and insects and Professor Tissa H. Illangasekare, senior water resources scientist".

Tissa Illangasekare is a world renowned researcher and experimentalist in the water resources area. He is known for his unique ability to combine innovative scientific theory with precise measurement techniques and innovative experiments. These methods have led to significant progress in a number of different areas of groundwater hydrology. His research has developed theories and models to apply our knowledge of small-scale processes to real, large-scale problems of groundwater hydrology. This is necessary, for example, to understand the spread of environmental pollution and to eventually rehabilitate environments effectively.

\section{Honours and recognitions}

- $\quad$ Elected to the Board of Directors of CUAHI (The Consortium of Universities for the Advancement of Hydrologic Science)- 2009

- Elected as the Chair of the Gordon Research Conference on Flow and Transport in Porous Media to be held at Oxford University in 2010 .

- Appointed to the External Science Advisory Board of the Hydrologic Observatory (HOBE) in Denmark

- Fellow of the American Geophysical Union

- Fellow of the American Society of Civil Engineers

- Received Board Certification by eminence from the Environmental Engineer, the American Academy of Environmental Engineers

- Fellow of the American Association for Advancement of Science (AAAS) 
Over the years he has supervised over 40 M.Sc. theses, $25 \mathrm{Ph} . \mathrm{D}$. theses and 14 post-doctoral researchers.

In 2005, Prof. Illangasekare led a joint USNSFSLNSF team of scientists that investigated the impacts of the December 2004 tsunami on the coastal groundwaters of Sri Lanka. The research findings and recommendations arising from this case study have now been published internationally.

The Editorial Board of the JNSF congratulates him on this honour and wishes him success in his future endeavours.

\section{Ananda Gunatilaka}

